\title{
ONLINE LEARNING CHALLENGES POSTGRADUATE CERTIFICATE IN EDUCATION HISTORY STUDENTS FACED DURING COVID-19 AT THE UNIVERSITY OF ZULULAND
}

\author{
DOI: http://dx.doi.org/10.17159/2223-0386/2020/n24a7 \\ Mbusiseni Celimpilo Dube \\ University of Zululand, Empangeni, South Africa \\ dube.mpilo@yahoo.com \\ ORCID No.: 0000000194510455
}

\begin{abstract}
This paper intends to share empirical challenges of Postgraduate Certificate in Education (PGCE) History students faced during COVID-19. COVID-19 was characterised by, amongst other things, social distancing, which put lectures on hold in favour of online learning. A group of 32 students participated in the study. Data were collected through narrative inquiry, and a thematic data analysis method was used. The study revealed that PGCE history students faced challenges of adapting to and accessing online learning and library materials, an expectation to do a lot of academic work, individual instead of classroom or library learning, unconducive home learning space, lack of parental support, and financial constraints. Therefore, this study concludes that students struggled to cope with online learning and recommends that institutions of higher learning should consider the above challenges when undertaking online learning under COVID-19 conditions in future.
\end{abstract}

Keywords: Online learning; Challenges; PGCE History students; COVID-19; Lectures; Teaching.

\section{Introduction}

The outbreak of the corona virus pandemic in 2019 (COVID-19) came with numerous consequences. Amongst these was the prohibition of lectures, which meant that students could not have face-to-face interactions with lecturers and fellow students. The banning of lectures was in line with social distancing, which was one of the means to curb the spread of COVID-19 as a global pandemic (Clerkin Fried, Raikhelkar, Sayer, Griffin, Masoumi \& Schwartz, 2020). The prohibition of lectures resulted in the forced introduction of online learning to help students continue 
with their education. Scholars have presented different definitions of the concept "online learning". For example, Benson (2002) and Carliner (2004) describe online learning as access to learning experiences via the use of some technology devices, whereas Anshari, Alas, Sabtu and Hamid (2016) refer to online learning as electronic learning (e-learning) or mobile learning (m-learning). Thus, online learning can simply be referred to as education that takes place over the internet, and may be called e-learning. Indeed, the United States Department of Education (2010) defines online learning as learning that takes place partially or entirely over the internet. All these definitions consist of three elements: technology, electronics and the internet. This suggests that online learning depends on these elements. This may suggest that students should have electronic devices like laptops, computers, desktops and smartphones for them to access online learning. In addition, students should have access to network and data for connectivity. So, without technological devices, network and data, students may struggle with online learning.

Online learning can be used to manage the processes of teaching and learning through information and communication technology (ICT) (Anshari, Alas, Sabtu \& Hamid, 2016). It can be handy in managing teaching and learning processes if all parties involved are well informed about it. Anshari and Alas (2015) argue that the adoption of online learning programmes in education generally provides a new experience for students. The demand for online learning is derived from a push "to provide quality education to all students, regardless of location and time" (Chaney, 2010: 21). Being away from the university campus should, therefore not necessarily be a conundrum for students. Hence Gilbert (2015) contends that online learning has the potential to create educational opportunities for individuals who may have faced unsurpassable barriers. Without the introduction of online learning after the outbreak of COVID-19, students may not have received education owing to social distancing.

The Postgraduate Certificate in Education (PGCE) History students who participated in this study registered for full-time face-to-face classes and were affected by the outbreak of the COVID-19 pandemic. They were forced to promptly adapt to online teaching and learning for them to qualify as teachers. They had to, at short notice, acquire technological devices and data in order to cope with online learning. PGCE History students already hold BA degrees with history as a major (DHET, 2011). Students with a BA degree are expected to have acquired sufficient content 
knowledge in history for them to be admitted into the PGCE programme (Nomlomo \& Sosibo, 2016). However, they still need to develop their pedagogical and practical knowledge (DHET, 2011, 2015). The PGCE is therefore a generalist qualification that is intended to cap a subject specialist undergraduate degree qualification (Lange \& Singh, 2010). The general purpose of the PGCE in this regard is established through national policy (Mukeredzi \& Sibanda, 2016). The aim of the PGCE professional qualification is further to equip students with the competencies, knowledge and skills needed to teach disciplinary knowledge to learners (Bertram, Mthiyane, \& Mukeredzi, 2013). Hence, the PGCE curriculum constitutes three key parts: core education and professional studies modules, teaching specialisation modules, and teaching practice (University of KwaZuluNatal, 2006).

At the University of Zululand, a rural higher education institution in northern KwaZulu-Natal build under apartheid for Africans, the PGCE History students were hit hard by the outbreak of COVID-19 since they did not have pedagogical background knowledge, unlike Bachelor of Education (B.Ed.) students who are exposed to pedagogy and its dynamics. For this reason, since PGCE History students are exposed to pedagogical knowledge for the first and last time in a one-year duration certificate, they then to rely heavily on their lecturers for guidance and support to complete. With online learning and teaching the PGCE History students had to learn on their own, without face-to-face contact with their lecturers. In their endeavours to complete their certificates in one year, coupled with the dearth of background knowledge of online learning, they experienced some challenges. By "challenges" the researcher means difficulties in undertaking online learning successfully. The inability to cope with these challenges meant that the students might not complete their qualification and secure jobs. The aim of this article was, therefore, to explore the challenges that PGCE History students faced during COVID-19, and determine how these challenges impacted on their studies.

\section{Literature review}

A literature review constitutes the body of knowledge on the topic of research interest, and helps the researcher to acquire an understanding of what has already been done around it - how it has been researched, and what the key issues are (Hart, 2018). For these reasons, this study reviewed 
the literature relating to online learning and its challenges.

Since online learning looks different to traditional face-to-face learning, there are issues to consider for it to succeed. For example, replication of collaborative learning within an online environment (Tan \& Chen, 2020) could be a drawback for students. There were more chances that students could not work together collaboratively as it would have been the case with traditional learning, and this could affect students' performance. Also, accessibility issues, like internet connectivity, and the availability of technological devices like, laptops and smartphones, (Aboagye, Yawson, \& Appiah, 2020; Farooq, Rathore, \& Mansoor, 2020) could have an impact.

Other issues that can be questionable with online learning are academic rigour and the quality of instruction (Gilbert, 2015). There is no assurance at all academics/online instructors apply the same rigour as they do with face-to-face learning. If online learning does not maintain academic rigour, it might hinder teaching and learning. Besides academic rigour, the quality of instruction is another issue that needs consideration when one talks about online learning. It is the responsibility of online instructors to ensure the quality of online teaching. If online instructors do not ensure the quality of their teaching, online learning may not be effective. In this regard a lack of proper training (Farooq et al., 2020) in online teaching and learning may result in poor teaching, thus affecting academic rigour and the quality of instruction.

Gilbert (2015) argues that the development of community and peer interaction, that is prevalent and significant in traditional learning, may be doubtful in online learning. He goes on to argue that active community and peer interaction may lead to high persistence and learning satisfaction, which may not be the case with online learning, which may be characterised by lower persistence rates informed by lack of community and social connectedness in the online environment. Online socialisation entails a learning process of enculturation into a discourse community in which students must develop the ability to engage with content according to set norms and conventions (Starfield, 2001). This thinking is echoed by Arasaratnam-Smith and Northcote (2017), who argue that online learning falls short of the richness and complexity of face-to-face learning, and nonverbal communication suffers greatly.

With reference to the above, Salmon (2013) presents a five-stage framework of online learning. The first stage is access and motivation, 
which encompass setting up and accessing the system, as well as welcoming students, and encouraging them to do online learning. The second stage is online socialisation, whereby students can send and receive messages, thus familiarising themselves with online learning. The third stage is information exchange and searching, which entail facilitating tasks and supporting use of online learning materials. The fourth stage is conferencing and facilitating the process by which students are developed to conference amongst themselves and with their lecturers so that lecturers can facilitate online lessons. The fifth and final stage is development, and it is about providing links outside closed conferences by supporting and responding to questions that students may have. These stages suggest that for online learning to be successful, participants need to be supported through a structured developmental process (Salmon, 2013), something that was lacking under COVID-19 emergency remote teaching.

A further challenge to online learning is the "one size fits all" approach, which does not seem do cater for individual differences (Gillett-Swan, 2017). Students are unique, hence even their learning capabilities differ. If online instructors or lecturers use the same approach, that can influence the effectiveness of online learning. Different approaches should be employed for different students to achieve maximum learning. Additionally, Orlando and Attard (2015) argue that online learning depends on the types of technology in use at the time, and the curriculum content being taught. The incorporation of technology in learning provides additional factors for consideration in terms of teaching pedagogy and construction of learning experiences. In this regard Jacobs (2013) suggests that it is important to identify the type of student enrolled in the course in order to design an appropriate interaction system that will allow the students not only to learn but also to enjoy the experience. For example, students with low reading abilities may find the heavy text and writing curriculum of online teaching and learning to be a challenge (Donlevy, 2003), since online learning requires students to read and write intensively. Also, according to Boling, Hough, Krinsky, Saleem and Stevens (2012), online learning should encompass higher-order cognitive skills as opposed to simply transferring content to students. This may be a challenge for those students who are not well versed in higher-order cognitive skills.

Jaques and Salmon (2007), as well as Davidson (2015) argue that anxiety associated with using technology, be it being out of a comfort zone, perception of inequity and the perceived inability to have or difficulty 
in having peer interaction may be another challenge for online learning. Anxiety amongst students owing to online learning may be a common issue for online learning beginners since they are unfamiliar with it, and it can impede the success of online learning. To counter anxiety issues, Parker (2003) asserts that students should become comfortable as active learners. If students are anxious they may continue to be passive learners.

Online learning can also leave students in an isolated place when they have varying levels of competence and proficiency (Gillet-Swan, 2017) when using technology. These varying levels can also affect their confidence in online learning (Anshari et al., 2016; Gillet-Swan, 2017). Taking into cognisance that with online learning there is a lack of community and social connectedness in the learning environment (Rovai, Wighting, \& Liu, 2005), students may find online learning challenging. With their differing proficiency in technology, working in silos may make students even more uncomfortable. To support their argument, Rovai et al. (2005: 04) contend that "online students feel a weaker sense of connectedness and belonging than on-campus students who attend face-to-face classes". Donlevy (2003) strongly argues that the absence of peer interaction can harm some aspects of the learning process.

Some students rely on collaborative learning for their educational success. With the advent of online learning group discussions do not appear to be a common practice (Jaques \& Salmon, 2007). In this regard Savenye (2005) argues that students' lack of independence with online learning made for lower success rates. Students who encounter some challenges with online learning may not get assistance from fellow students as they usually did in face-to-face interactions. In other words, platforms where students can share their learning difficulties may be limited, or not feasible at all, and that can cripple their effort. However, online learning can succeed if students do not lack self-motivation and self-direction, as Gilbert (2015), Parker (2003) and Savenye (2005). In contrast, Chaney (2001) contends that students who lack motivation, whether intrinsic or extrinsic, can easily lose sight of their original goal. In this regard You and Kand (2014) affirm that students with a lack of self-regulation tend not to assign enough time to complete given activities. In short, online learning requires students to be self-motivated, self-directed and self-regulated. If they lack these attributes, online learning may be a fiasco. 
Online learning can succeed if those involved undergo continuous training and support. This suggests that online instructors and students should be familiar and comfortable with the latest technological developments and related software (Fish \& Wickersham, 2010). The effectiveness of online learning therefore depends not only on students, but, also on lecturers. If lecturers are abreast of technology they may undertake the online teaching and learning process efficiently. Fish and Wickersham (2010) go on to affirm that online instructors networking with others who teach such courses universities can improve the effectiveness of online learning. If online instructors' network with others, they can bolster their own technological knowledge and skills, thus improving online learning.

Another challenge is the issue of the "haves" versus the "have nots", which is due to the lack of funds to gain access to the technology and what it entails (Gilbert, 2015). In order to address this challenge, Gilbert (2015) argues that increasing the ratio of computers and other electronic devices to students may ultimately lead to the disadvantaged gaining access to the global knowledge that is available on the internet. In a nutshell, in order to bridge the gap between the "haves" and "have nots", and for online learning to be effective, students should be furnished with computers and other electronic devices. In addition to these, understanding learning styles and self-behaviour is pertinent to determining success in undertaking online learning (Gilbert, 2015). Even if a student is in possession of an electronic device, if he or she does not understand learning styles and does not behave well, online learning becomes pointless.

When Adedoyin and Soykan (2020) conducted a study on the COVID-19 pandemic and online learning, they found that human distractions were a challenge for students. This study reported that family members and friends interrupted students when they, for example, undertook assessment activities at home. These interruptions are more common with female students, who, in addition to their academic work, are expected to undertake household duties (Farooq et al., 2020). Additionally, online instructors lamented the heavy workload that emanate from online teaching. This was heavy for online instructors because they were used to meeting students face-to-face. In this regard Jacobs (2013) asserts that online instruction takes more time to design and implement than traditional learning.

Jacobs (2013), also reported on the challenges of online courses in developing appropriate methods for online learning. Considering the fact 
that lecturers who suddenly became online instructors were used to the traditional learning process, undertaking online learning meant they had to change their teaching methods. This became a challenge for them since they were not properly and gradually orientated to online learning but were just parachuted into it.

\section{Theoretical base: Schlossberg's transition theory}

The degree to which students transit from one educational format to another has a bearing on how they can address challenges they encounter in the process. Their transition from high school to higher education may be, for example, be coupled with challenges caused by unfamiliar teaching and learning styles, and a new environment and workload, amongst other things. To counter and meet these new learning challenges from a new environment, Nancy Schlossberg introduced "transition theory" in 1981. This theory alludes to issues that relate to transition, the individual student, and the environment in order to show the degree of impact such a transition has had on a student at a particular time and place (Carroll \& Creamer, 2004). Surely, in relation to transition from face-to-face to online learning, PGCE History students come across challenges.

Goodman, Schlossberg and Anderson (2006) argue that unanticipated transitions, which encapsulate unpredictable transitions, may be challenging since the people involved are forced to adapt to a new situation they never predicted or prepared themselves for. In other words, with this kind of transition those involved have no option but (compelled by circumstance) to adapt. This is the situation PGCE History students found themselves in when face-to-face classes were suspended due to COVID-19 AT THE University of Zululand.

Since transition theory alludes to issues related to this article, it was deemed an appropriate theoretical lens to explore the kind of challenges the transition from face-to-face to online learning had on PGCE History students, who lacked proper knowledge and skills of how to cope with online learning. It was therefore crucial to explore the dynamics of transiting from face-to-face to online learning in order to understand its challenges.

\section{Research methodology}

A case study design was employed to explore the challenges that PGCE 
History students faced during the COVID-19 pandemic. Since the interest in this study was not on quantifying but providing in-depth experiences and understanding of the respondents from their own point of view (Dube, 2019), a small-scale study was approached qualitatively. It generated data using narrative enquiry, which is about people narrating stories about their challenges. Narrative inquiry helps to understand and present real-life experiences through the stories of research participants (Wang \& Geale, 2015), thus allowing a rich description of these challenges, and an exploration of the meanings that the participants derive from their challenges (Wang $\&$ Geale, 2015). Since interpretivists view the world through a "series of individual eyes", and choose participants who "have their own interpretations of reality" to "encompass the worldview" (Thanh \& Thanh, 2015:26), using the interpretive paradigm was apposite for this study.

There were 75 PGCE History students, and they were all requested to participate in the study by writing, in a digital format, about "My online learning challenges during the COVID-9 pandemic". However, only 32 students chose to participate. All these students were black Africans, most of whom were women. The racial demographics of the participants is a legacy from the past when the University of Zululand were created. Most of the participants were older than 30 .

Data generated were analysed using thematic coding. In doing so, the researcher went through the responses repeatedly for more understanding, and categorised data into themes, thereafter analysing them with the intention to develop an understanding of the challenges PGCE History students faced in transition to online teaching and learning.

\section{Ethical considerations}

The researcher sought ethics clearance before conducting research, and issued informed consent letters through emails and the learner management system to students, all of whom signed and returned them to the researcher. The document explained the purpose of the study, and how it would be conducted. Students were referred to as participants in order to protect their identity. Yip, Han and Sng (2016) argue that researchers should 'protect the life, health, dignity, integrity, right to self-determination, privacy and the confidentiality of personal information of the participants in research. 


\section{Research findings}

The data for this empirical qualitative study revealed six major online learning challenges that PGCE History students at the University of Zululand faced during COVID-19.

\section{Accessibility}

The analsyis of the online narrative accounts revealed that some of the participating PGCE History students had difficulties in adapting to and accessing online learning and study material from the university. The lockdown also meant that PGCE History students, like other students, could not access university facilities. As a result, they could not access study material from the library, and this worsened their stress since they were already struggling with internet connections for online learning. Since most of them lived in rural areas, connection to the internet was a serious challenge owing to low or no network at all. Hence, some were forced to walk long distances to, for example, the top of a hill so as to connect to a network. Due to network issues some students failed to submit activities given to them by their lecturers because they could not connect to the internet, and some submitted after the due date. In some rural areas from which the participating students came from, there was no electricity at all. Online learning depends on internet connection and electricity, so if both are not functional, students will surely face a challenge, and this was the case for many of the participants in this study.

\section{Heavy workload}

Online learning compelled PGCE History students to remain at home and continue with their studies. In the process, as gleaned from the data, they ended up being bombarded with a mountain of academic work. This many a time had to be done within a short space of time. Some students even lamented that online instructors were not considerate of their situation. Some students explained in the narratives they submitted that they were frustrated by the excessive workload, and some almost gave up.

\section{Individual learning}

Online learning gave way to individual learning, which most PGCE History students were pedagogically and culturally unfamiliar with. Some students explained that they were expected to read and gather information 
on their own. This became a challenge as they claimed that they struggled with self-regulation and connectivity and support from their peers. Some struggled with individual learning because they had no study material. Hence, a trend that seemingly emerged is of students that were confused and demotivated by online learning.

\section{Home distractions}

Another challenge to online learning was the home distractions which made home a learning space unconducive to work. For most students, staying at home had many challenges. Some lamented that they stayed with their unemployed siblings, who were always home, so they could not use rooms for academic work. Other students, especially female students, mentioned that they were expected to look after children, and were repeatedly disturbed by family members, which denied them a chance to engage with their academic work. Some lived in homes where there was a lot of noise they could not control, so it was a challenge to focus and do academic work freely. Some students did not have enough space at home to undertake academic work.

\section{Lack of parental support}

Another finding suggests that some parents did not offer support for their children who were PGCE History students. According to some students, some parents did not allow them time to do and complete academic work; instead they expected them to perform all the daily home chores, although they were supposed to write tests and academic activities. Some parents could not even ensure that no one disturbed them when busy with academic work. For example, some students said that they had to do academic work while cooking because parents did not understand them reserving time for academic work. The lack of support from parents made online learning difficult for learners.

\section{Economic conditions}

What also emerged from the data was that the participating PGCE History students' economic conditions were a challenge for online learning. Some students complained that they struggled to buy data in order to connect to the internet for online learning. Other students mentioned that they did not have laptops they could use for online learning. With their inability to 
buy data, some students could not communicate with other students and lecturers about teaching and learning activities. They complained that they could not share information, ask for clarity, raise concerns and discuss academic issues.

\section{Discussion of findings}

Being forced by circumstance to promptly switch to online learning without being prepared for it, precipitated difficulties for PGCE History students to access and adapt to online learning. Salmon (2013) argues that before students can engage with online learning they need to undergo a structured developmental process in different stages, and access to online learning is the first stage. The assertion by one of the participants that "the movement of classes online caused anxiety to me since I never got training about it" justified Salmon's argument. The PGCE History students never received training in online learning so as to orientate them accordingly. As Farooq et al. (2020) claims, the lack of proper training can affect online learning negatively. The anxiety about online learning was not peculiar, since PGCE History students needed to move out of their comfort zone (Jaques \& Salmon, 2007; Davidson, 2015), that of face-to-face interaction with lecturers and peers in an on-campus setting.

Another participant affirmed that "it was difficult to get used to online learning within a short space of time, and be expected to write and submit activities". Online learning needs different approaches since students may be at different levels. Hence Orlando and Attard (2015) argue that online learning does not need a "one size fits all" approach. Online instructors need to bear in mind that their students' level of abilities and means to work in such an environment may vary, so they need to employ various approaches to accommodate students at all levels of knowledge.

One other issue that made online learning challenging was the network connectivity, which was either weak or non-existent at all. This was affirmed by a participant who said: "I had a problem with online learning since I am from a deep rural area where there is low network coverage, and sometimes there is no network at all". Thus, the rural location of some students at times denied them access to online learning so that they could not even submit academic work in time, and failed assessment activities. This was vividly expressed by a PGCE History student who stated: 
I started answering quiz questions, but before reached question 10 the network dropped off. It came back after a while, so I continued writing, but before I finished all questions the time was up, and I could not finish writing. The results came back, and I had got 20\%. I locked myself in my room and cried.

One can imagine the student being fully prepared for the test, but due to network failure, failing it. Another participant explained: "The greatest challenge of them all was network glitches, and I could not submit my work on time". Network connectivity issues stood in the way of some PGCE History students' intention to create and exchange content for learning, as argued by Salmon (2013), and Chung and Paredes (2015). The network problem in online learning is also emphasised by Aboagye et al. (2020) and Farooq et al. (2020), who argue that accessibility to the network determines the possibility and success of online learning. PGCE History students could not progressively acquire content knowledge, and interact with other students who could contribute new ideas, opinions and experiences (Rosen, 2010) because of poor or no connection at all.

Access to on campus resources and specially the library, be it the physical structure or an online equivalent, also became a problem for some PGCE History students. One participant complained that "in terms of studying, it was hectic because one could not access most required sources like books from the library". Salmon (2013) argues that without good access to study material, online learning can be a fiasco. If the library was accessible, PGCE History students would have used it to supplement difficulties of online learning. One participant reiterated that "libraries as sources of information were closed, so it became hard for me to do my academic work". Even if students were self-motivated and self-directed (Parker, 2003; Gilbert, 2015) without access to libraries they could not do anything to bridge the gap between online and face-to-face learning. Access to libraries would have helped those students who had network connectivity problems because they would have used libraries to supplement online learning, but the closure brought more dilemmas. This was explained by one of the students: "It is hard to do academic work in rural areas because there is no Wi-Fi and network, and we are not allowed to go to libraries to do research".

An analysis of the data also revealed that some PGCE History students were burdened by having a heavy workload to cope with amid COVID-19. Not only was this caused by the introduction of online learning, but it was 
also due to academics who wanted to finish their work programmes on time and who did so by dumping material online. One of the PGCE History students explained: "The amount of work, assignments given and slides to study was overwhelmingly large". This overwhelming amount of work frustrated some students, and they were left with not knowing what to do. In this regard a participant explained: "I was frustrated with the volume of work given by our lecturers". With a bulk of work to be done, and lack of community and social connectedness in the learning environment (Rovai et al., 2005), the PGCE History students suffered since they did not have someone to help them with academic work. It is for this reason that Gilbert (2015) argues that the lack of online community may be a deficit in the online learning environment. Owing to the amount of work given to PGCE History students, one of them even felt betrayed, and blamed lecturers: "There was a lot of work to do. I sometimes even say lecturers don't think for us, they want us to fail because they give us work, yet they know exactly the problems we are facing now". Maybe this outcry was informed by the students' lack of familiarity with and autonomy in online learning that Savenye (2005) talks about.

The researcher indicated earlier that online learning gave way to individual learning, which meant that students had to rely on themselves for knowledge acquisition and development, with little or no assistance. Some students were unhappy with individual learning since they were unfamiliar with it. The challenge being that chances of replicating collaborative learning within an online environment (Tan \& Chen, 2020) are too scanty. For one participant, "being alone as a university student at home is hard, because if you face some difficulties, there's no one to help, unlike on campus; with everyone around you, you will always get help". Another PGCE History student explained: "I'm familiar with attending lectures, so at first it was so difficult to study by myself without a lecturer in front of me". These two comments proved that some PGCE History students experienced difficulties in coping with individual learning. Students value the help they get from their peers, but individual learning robbed them of that. The data also revealed that the PGCE History students depended greatly on lecturers in acquiring pedagogical knowledge and skills. Some students felt that individual learning hindered their academic performance. One participant explained: "The pandemic forced us to learn alone, and that threatened my academic performance since I had to do work on my own". In this regard You and Kand (2014) argue that students who lack 
self-regulation do not assign enough time to complete given activities. There is a great likelihood that PGCE History students had a problem with individual learning because they have not learnt how to self-regulate. This tallies with the views of Rovai et al. (2005), who suggest that without a sense of connectedness online students may vulnerable, especially since individual learning may be in contrast to peer interaction (Donlevy, 2003).

Another online learning challenge was home disruptions, which made learning unconducive for PGCE History students. Undertaking learning at home proved not to be working for most PGCE History students who participated in this study. The data revealed numerous reasons why studying at home had negative effects on most of the students. One participant complained: "Well, my point is that at home I don't have as much time to focus on my academic work as when I'm on campus. Too much time is wasted on home duties". Another pointed out that: "At home I got disturbed repeatedly while trying to concentrate and do academic work". For another student: "Staying at home has not been a conducive place for online learning because I come from a big family where there is a lot of noise which can't be controlled, and there is no way of learning". Another participant lamented: "The other challenge we have since we are at home is that our parents do not understand if you spend too much time on your cellphone". Space was also an issue as one participant explained: "I share a room with my unemployed siblings, so I have to stay up till late so that they fall asleep, and I can start studying". Farooq et al. (2020) argue that in addition to academic work, female students are expected to undertake household duties, and this is stressful for them. Parents do not understand if students spend a lot of time on a cell phone, because they do not know anything about online learning. Even if PGCE History students could regulate themselves to complete the given activities (You \& Kand, 2014), if the home situation is beyond their control, there is little they can do. Chaney (2001) talks about students who may lack so much motivation that they can easily lose sight of their original goal. However, these PGCE History students did not lose sight of their goal, but the domestic situation they found themselves in was beyond their control. In other words, these students were fully prepared to undergo the knowledge construction which Salmon (2013) regards as the fourth stage of technological development; but the obligation to do home duties stood in their way.

One other issue that made online learning challenging for PGCE History students was the lack of support from parents. Parents did, generally 
speaking, not bother allowing the students who participated in this study time to do academic work; the only thing they cared about was their undertaking and completing home chores. This was explained by two female participants:

I had to study while cooking at the same time; while I'm busy studying, my parents call me several times, asking me to do certain things for them. And: At home I have to clean the house, cook, fetch water, do washing and take care of children, and I can't study at night because I need time to rest because I'm exhausted.

These comments illustrate that certain parents did not support students by allowing them time to do academic work, possibly because of not understanding what online learning entails which was mixed with tradition, culture and patriarchy. According to Vasquez, Patall, Fong, Corrigan and Pine (2016), parents should play an important role in shaping a student's academic functioning. Jelas, Azman, Zulnaidi and Ahmad (2016) argue that the academic achievement of students depends on internal and external support. They classify family as one of the external support structures needed by students to achieve better.

The last issue that made online learning challenging was the economic situation of many PGCE History students. Most of them struggled to obtain data for network connectivity or laptops because they could not afford it. Some of them missed certain assessment activities, and others submitted work late because they did not have data to connect to the network. In relation to this one student explained: "The other challenge was that one of data. Online learning needs too many data bundles that I could not afford as a student, hence I missed some important information from my lecturers". A similar sentiment was shared by another participant: "The need for data bundles left me frustrated because I couldn't go a day without them so as to stay updated about module issues. So I ended up borrowing money to buy data. Sometimes if I failed to buy data I ended up not submitting an assignment on time, and was penalised". Gilbert (2015) argues that being a "have not" owing to lack of funds to gain access to the internet is a challenge for online students. Unfortunately for the students in this study, their economic situation prevented them from engaging with content according to set norms and conventions (Starfield, 2001). According to Gilbert (2015), the ratio of computers and other electronic devices should be increased for the disadvantaged to gain access. This means that giving PGCE History students laptops and data could have helped them with their 
outcry about online learning and its accessibility.

\section{Conclusion}

The transition, due to COVID-19, compelled PGCE History students at the University of Zululand, to alter their life and learning styles, but they did not find it easy to cope with the new way of online learning. This study concludes that the failure to slowly and smoothly orientate PGCE History students in their transition to online learning resulted in some serious drawbacks. The inaccessibility of online learning robbed most of the students of the pedagogical and content knowledge, and the inaccessibility of study material made online learning a challenge. PGCE History students could not cope with academic work from online instructors, while homebased, individualised learning did not work for some students since they were used to collaborative learning. Home disruptions were a big challenge for students in their detrimental impact on online learning. Some parents did not understand their role in online learning. Students' financial difficulties were a big impediment to such learning. No easy solution can be recommended to the challenges faced by the History PGCE students in this study. However, what this study has done was to lay bare the challenges faced by students at a previously disadvantaged higher education institution in the transition from face-to-face to online learning due to the COVID-19 pandemic.

\section{References}

Aboagye, E, Yawson, JA \& Appiah, KN 2020. COVID-19 and E-learning: The challenges of students in tertiary institutions. Social Education Research, 1-8.

Adedoyin, OB \& Soykan, E 2020. COVID-19 pandemic and online learning: The challenges and opportunities. Interactive Learning Environments, 1-13.

Anshari, M \& Alas, Y 2015b. Developing pervasive online learning resources: Case mobile learning. Paper presented at NIDA International Conference, 6-7 August 2015, Bangkok, Thailand.

Anshari, M, Alas, Y, Yunus, N Sabtu, N \& Hamid, M 2016. Online learning: Trends, issues and challenges in the Big Data Era. Journal of e-Learning and Knowledge Society, 12(1):121-134. Available at www.learntechlib.org/p/171433/. Accessed on 16 December 2020. 
Arasaratnam-Smith, LA \& Northcote, M 2017. Community in online higher education: Challenges and opportunities. Electronic Journal of e-Learning, 15(2):188-198.

Benson, A 2002. Using online learning to meet workforce demand: A case study of stakeholder influence. Quarterly Review of Distance Education, 3(4):443452.

Bertram, C, Mthiyane, N \& Mukeredzi, TG 2013. 'It will make me a real teacher': Learning experiences of part-time PGCE students in South Africa. International Journal of Educational Development, 33(5):448-456.

Blackley, S \& Sheffield, R 2015. Digital andragogy: A richer blend of initial teacher education in the 21st century. Issues in Educational Research, 25(4):397-414.

Boling, EC, Hough, M, Krinsky, H, Saleem, H \& Stevens, M 2012. Cutting the distance in distance education: Perspectives on what promotes online learning experiences. Internet and Higher Education, 15(2):118-126.

Carliner, S 2004. An overview of online learning, 2. Amherst, MA: Human Resource Development Press.

Carroll, T, \& Creamer, D 2004. The significance of an orientation program: Addressing the problem of retention. Available at http://filebox.vt.edu/users/tramaine/ Theory\%20to\%20Practice\%20paper\%20index.htm. Accessed on 28 April 2008.

Chaney, EG 2001. Web-based instruction in a rural high school: A collaborative inquiry into its effectiveness and desirability. NASSP Bulletin, 85(628):20-35.

Chung, KSK \& Paredes, WC 2015. Towards a social networks model for online learning \& performance. Journal of Educational Technology \& Society, 18(3):240-253.

Clerkin, KJ, Fried, JA, Raikhelkar, J, Sayer, G, Griffin, JM, Masoumi, A \& Schwartz, A 2020. COVID-19 and cardiovascular disease. Circulation, 141(20):16481655.

Davidson, R 2015. Wiki use that increases communication and collaboration motivation. Journal of Learning Design, 8(3):94-105.

DHET, R 2011. National Qualifications Framework, Act 67 of 2008: Policy on the Minimum Requirements for Teacher Education Qualifications. Pretoria, State Printer.

DHET, S 2015. Reflections on higher education transformation. Higher Education Summit, 1-24. 
Donlevy, J 2003. Teachers, technology and training: Online learning in virtual high school. International Journal of Instructional Media, 30(2):117-121.

Dube, MC 2019. Chronicles of postgraduate certificate in education students on mentoring process: A lesson from teaching practicum. Gender and Behaviour, 17(3): $13610-13626$.

Farooq, F, Rathore, FA \& Mansoor, SN 2020. Challenges of online medical education in Pakistan during COVID-19 pandemic. J Coll Physicians Surg Pak, 30(6): 67-69.

Fish, WW \& Wickersham, LE 2010. Best practices for online instructors. The Quarterly Review of Distance Education, 10(3):279-284.

Gilbert, B 2015. Online learning revealing the benefits and challenges. Master's dissertation, St. John Fisher College, Rochester, NY. Available at https:// fisherpub.sjfc.edu/education_ETD_masters/303. Accessed on 22 November 2020 .

Gillett-Swan, J 2017. The challenges of online learning: Supporting and engaging the isolated learner. Journal of Learning Design, 10(1):20-30.

Gong, Y, Kim, TY, Lee, DR \& Zhu, J 2013. A multilevel model of team goal orientation, information exchange, and creativity. Academy of Management Journal, 56(3):827-851.

Goodman, J, Schlossberg, NK \& Anderson, ML 2006. Counselling adults in transition: Linking practice with theory, 3. New York: Spring.

Hart, C 2018. Doing a literature review: Releasing the research imagination. London: SAGE.

Hiltz, SR \& Turoff, M 2005. Education goes digital: The evolution of online learningand the revolution in higher education. Communications of the ACM, 48(10):59-64.

Jacobs, P 2013. The challenges of online courses for the instructor. Research in Higher Education Journal, 21:1-18.

Jaques, D \& Salmon, G 2007. Learning in groups: A handbook for face-to-face and online environments. Abingdon: Routledge.

Jelas, ZM, Azman, N, Zulnaidi, H \& Ahmad, NA 2016. Learning support and academic achievement among Malaysian adolescents: The mediating role of student engagement. Learning Environments Research, 19(2):221-240. 
Lange, L \& Singh, M 2010. Equity issues in quality assurance in South African higher education. In: M Michaela (ed.), Equity and quality assurance: A marriage of two minds. New trends in higher education. Paris: International Institute for Educational Planning, UNESCO:37-74.

Lee, J \& Bonk, CJ 2016. Social network analysis of peer relationships and online interactions in a blended class using blogs. Internet and Higher Education, 28:35-44. Available at doi.org/10.1016/j.iheduc.2015.09.001. Accessed on 22 November 2020.

Loannou, A, Demetriou, S \& Mama, M 2014. Exploring factors influencing collaborative knowledge construction in online discussions: Student facilitation and quality of initial postings. American Journal of Distance Education, 28(3):183-195.

Mayes, R, Ku, H, Adarasriworn, C, Luebeck, J, \& Korkmaz, O 2011. Themes and strategies for transformative online instruction: A review of the literature. Quarterly Review of Distance Education, 12(3):151-166.

Moore, JL, Dickson-Deane, C \& Galyen, K 2011. e-Learning, online learning, and distance learning environments: Are they the same? The Internet and Higher Education, 14(2):129-135.

Mukeredzi, TG \& Sibanda, D 2016. Part-time postgraduate certificate in education teacher-students: What do they bring to and expect from a formal South African teaching programme? Australian Journal of Teacher Education, 41(9):81.

Nomlomo, V \& Sosibo, Z 2016. From theory to practice: Beginner teachers' experiences of the rigour of the Postgraduate Certificate in Education programme. Perspectives in Education, 34(1):199-215.

Oblinger, DG \& Oblinger, JL 2005. Educating the net generation. Educause-Transforming education through information technologies. Available at http://net.educause. edu/ir/library/pdf/pub7101.pdf. As accessed on 22 November 2020.

Orlando, J \& Attard, C 2015. Digital natives come of age: The reality of today's early career teachers using mobile devices to teach mathematics. Mathematics Education Research Journal, 28:107-121.

Parker, A 2003. Identifying predictors of academic persistence in distance learning. USDLA Journal, 17(1):55-62.

Renda dos Santos, LM \& Okazaki, S 2016. Planned e-learning adoption and occupational socialisation in Brazilian higher education. Studies in Higher Education, 41(11):1974-1994. 
Rosen, LD 2010. Understanding the iGeneration and the way they learn. New York, NY: Palgrave Macmillan.

Rovai, AP, Wighting, MJ \& Liu, J 2005. School climate: Sense of classroom and school communities in online and on-campus higher education courses. Quarterly Review of Distance Education, 6(4):361-374.

Salmon, G 2013. E-tivities: The key to active online learning. London: Routledge.

Savenye, WC 2005. Improving online courses: What is interaction and why use it? (Undetermined). Distance Learning, 2(6):22-28.

Shakarami, A 2012. Online socialisation, language learning strategies and ESL learning in the digital world. Available at www.sciencerecord.com, 4(2):2-11. As accessed on 22 November 2020.

Starfield, S 2001. "I'll go with the group": Rethinking "discourse community" in EAP. In: J Flowerdew \& M Peacock (eds.), Research perspectives on English for academic purposes, 132-147. Cambridge: Cambridge University Press.

Stuart, HC, Dabbish, L, Kiesler, S, Kinnaird, P \& Kang, R 2012. Social transparency in networked information exchange: A theoretical framework. In: Proceedings of the ACM 2012 conference on computer supported cooperative work, Seattle. WA, February 2012, 451-460. New York, NY: Association for Computing Machinery.

Tan, DY \& Chen, JM 2020. Bringing physical physics classroom online - challenges of online teaching in the new normal. arXiv preprint, arXiv:2009.02705.

Thanh, NC \& Thanh, TTL 2015. The interconnection between interpretivist paradigm and qualitative methods in education. American Journal of Educational Science, 1(2):24-27.

Thomson, LD 2010. Beyond the classroom walls: Teachers' and students' perspectives on how online learning can meet the needs of gifted students. Journal of Advanced Academics, 21(4):662-712.

University of KwaZulu-Natal 2006. Council on Higher Education self-evaluation portfolio. Durban: University of KwaZulu-Natal, Faculty of Education.

US Department of Education, Office of Planning, Evaluation, and Policy Development. 2010. Evaluation of evidence-based practices in online learning: A metaanalysis and review of online learning studies, Washington, DC. Available at www.ed.gov/about/offices/list/opepd/ppss/reports.html. As accessed on 22 November 2020. 
Vasquez, AC, Patall, EA, Fong, CJ, Corrigan, AS \& Pine, L 2016. Parent autonomy support, academic achievement, and psychosocial functioning: A metaanalysis of research. Educational Psychology Review, 28(3):605-644.

Wang, CC \& Geale, SK 2015. The power of story: Narrative inquiry as a methodology in nursing research. International Journal of Nursing Sciences, 2(2):195-198.

Williams, KC, Cameron, BA, \& Morgan, K 2012. Supporting online group projects. NACTA Journal, 56(2):15-20.

Yip, C, Han, NLR \& Sng, BL 2016. Legal and ethical issues in research. Indian Journal of Anaesthesia, 60(9):684-688.

You, JW, \& Kang, M 2014. The role of academic emotions in the relationship between perceived academic control and self-regulated learning in online learning. Computers \& Education, 77:125-133. 